\title{
Thermal Shock Resistance of Bilayered YSZ Thermal Barrier Coating
}

\author{
Dong Heon Lee*, Tae Woo Kim**, Kee Sung Lee***, and Chul Kim**; \\ *Department of Automotive Engineering, Kookmin University, Seoul 02707, Korea \\ ${ }^{* *}$ School of Mechanical Engineering, Kookmin University, Seoul 02707, Korea \\ (Received May 18, 2018; Revised July 4, 2018; Accepted July 15, 2018)
}

\begin{abstract}
This study investigate changes in mechanical behaviors such as indentation load-displacement and hardness of thermal barrier coatings (TBCs) using cycling of thermal shock test. Relatively dense and porous TBCs on nickel-based bondcoat/super alloy are prepared using different starting granules, 204C-NS and 204NS commercial powers, and the effect of double layers of $204 \mathrm{C}$ NS on $204 \mathrm{NS}$ and $204 \mathrm{NS}$ on $204 \mathrm{C}-\mathrm{NS}$ are investigated. The highest temperature applied during thermal shock test is $1100^{\circ} \mathrm{C}$ and the maximum number of cycles is 1,200 . The results indicate that bilayered TBC showed a relatively mechanically resistant property during thermal shock cycles and that the mechanical behavior is influenced by the microstructure of TBCs by exposure to high temperature during tests or different starting granules.
\end{abstract}

Key words : Coatings, Thermal shock, Hardness, Mechanical properties

\section{Introduction}

$\mathrm{H}_{\mathrm{a}}^{\mathrm{i}}$ gh temperature components of static gas turbines such as the domestic combustor burner, blade, and vane are used at temperatures above $1100^{\circ} \mathrm{C}$, so the ceramic material yttria stabilized zirconia (YSZ) is used to coat the surface of the components with a coating $400 \sim 600 \mathrm{~mm}$ thick in order to protect the component from the high temperature.,2) Since ceramic coated gas turbine components form a dynamic system that needs to be operated at constant speed at high temperature, the components are exposed to cyclic fatigue, creep, and abrasions. Also, domestically, gas turbines are frequently operated under peak loads of power generation, so the high temperature components are commonly exposed to thermal shock environments with frequent heating and cooling. With regard to the lifespan of the thermal barrier coating, it has been reported that delamination occurs due to the formation and growth of thermally grown oxide layer (TGO) produced by contact between the base metallic material and the coating material; this process is the results of the propagation of oxygen in the external atmosphere into the coating. However, damage of the coating material due to surface abrasion and mechanical damage have also been widely reported. ${ }^{3-8)}$

There are many ways to fabricate a thermal barrier coating, including air plasma spray (APS), electron beam physical vapor deposition (EBPVD), and vacuum plasma spray (VPS); however, the air plasma spray method is most commonly used to coat components with complex shapes. This

\footnotetext{
${ }^{\top}$ Corresponding author: Chul Kim

E-mail : ckim@kookmin.ac.kr

Tel : +82-2-910-4685 Fax : +82-2-910-4839
}

method transports spheroidized ceramic powder to the nozzle via a carrier gas. After using high temperature plasma to melt or half melt the ceramic powder, the ceramic material is sprayed on the base material from a certain distance using high pressure from the plasma stream to coat the component. Thus, the size, shape, and particle size distribution of the initial powder have been reported to be closely related to the material properties of the final coating layer. Therefore, research was actively pursued with regard to various powders; ${ }^{2)}$ the fabrication of a coating material with optimized porosity is ideal to simultaneously satisfy the thermal barrier performance and the thermal and mechanical properties. For example, there is generally no mechanical property degradation from sintering at high temperature, phase transformation, stress variation during cooling, or abrasions.

However, whether a dense coating material or a relatively porous structure is better for enhancing the durability of the coating material has not been established yet because the thermal and mechanical properties exhibit contrasting behaviors according to the porosity of the coating material.

Numerous studies have been carried out on multi-layered structure materials, as such materials have the advantage of being able to create new characteristics by bringing together materials of different properties. ${ }^{7-9)}$ When integrating materials with different thermal expansion coefficients or moduli of elasticity, disadvantages can occur if coating layers can be easily damaged, and so the thickness of the properties of the coating layer and the base material have to be optimally designed. Various studies are being carried out on bilayered thermal barrier coatings; these materials are expected to provide a solution to the issue of contrasting thermal and mechanical properties. ${ }^{3,8)}$ When a single coat- 
ing layer was applied, the thermal properties were good but the mechanical properties were degraded (the reverse was also possible); however, when a bilayer coating is applied, it is expected that the thermal and mechanical properties will complement each other to produce a coating material with excellent thermal and mechanical properties.

In this study, the changes in the mechanical properties due to indentation after thermal shock tests were investigated in order to evaluate the mechanical behavior variations due to heat. Repeated exposures at the operation temperature $1100^{\circ} \mathrm{C}$ of the most commonly used gas turbines and at room temperature, along with a thermal shock environment similar to the actual operational environment, were carried out and the continuous and repeated thermal shock cycle number was varied. For each specimen, the mechanical properties were assessed through Vickers indentation and spherical indentation methods to observe the changes in the mechanical behavior due to thermal shock..$^{10,11)}$ Especially, in this comparative analysis study, coating materials of various porosity, depending on the initial powder type, were fabricated and the bilayered coating material was manufactured with one of the coating materials with different densities on the outermost surface.

\section{Experimental Procedure}

Figure 1 shows the experimental process used in this study. Ni Inconel heat-resistant alloy of 1-inch $(25.4 \mathrm{~mm})$ diameter and approximately $10 \mathrm{~mm}$ thickness was processed as the base material. To relieve the thermal expansion coefficient mismatch between the base material and the topcoat, a bondcoat (Ni-Cr-Co-Al-Y, AMDRY9625, Sulzer Metco Co.) with coefficient of thermal expansion approximately in the middle of those of the base material and the topcoat was applied to a thickness of $300 \mu \mathrm{m}$ via air plasma spray method. Sand blasting using alumina sand was conducted to enhance the adhesive strength between the base material and the bondcoat, and the surface of the produced bondcoat was also sand blasted. Two types of commercial YSZ powder, 204C-NS powder (8 wt\% YSZ, Sulzer Metco, Switzerland), with a relatively wide particle size distribution and hollow spherical shape and the 204NS (8 wt\% YSZ, Sulzer Metco, Switzerland), with a relatively narrow particle size distribution and filled spherical shape, were pre-

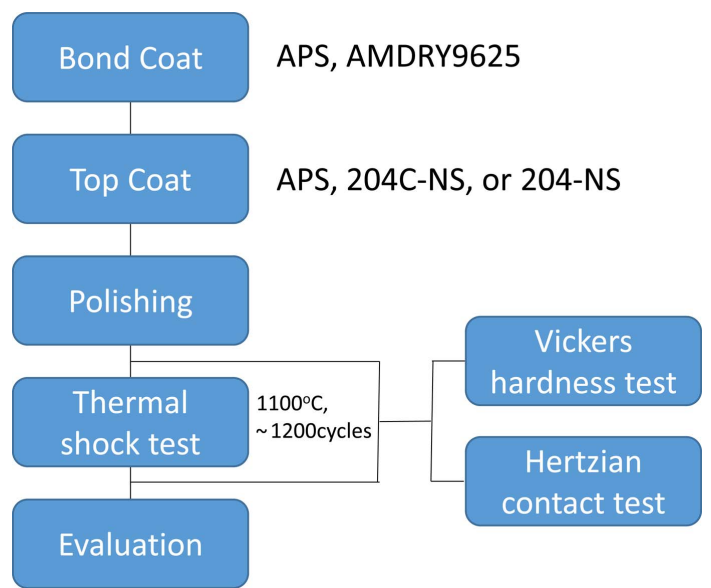

Fig. 1. Schematic diagram of experimental and analysis chart.

pared as shown in Fig. 2 to form the topcoat with different layers.

The air plasma spray method was used to fabricate a total of 4 types of specimens, which were single layered and bilayered according to the topcoat powder type. The 4 types of specimens prepared were a single layer coating fabricated with $204 \mathrm{C}-\mathrm{NS}$ powder, a single layer coating fabricated with $204 \mathrm{NS}$ powder, a $204 \mathrm{C}-\mathrm{NS} / 204 \mathrm{NS}$ bilayer coating in which the $204 \mathrm{C}-\mathrm{NS}$ powder was coated on top of $204 \mathrm{NS}$ powder coating, and a $204 \mathrm{NS} / 204 \mathrm{C}-\mathrm{NS}$ bilayer coating in which the $204 \mathrm{NS}$ powder was coated on top of $204 \mathrm{C}-\mathrm{NS}$ powder coating.

The air plasma spray method was carried out using the same process parameters as discussed below for all the coating materials in the coating fabrication process. Mixed gas of $\mathrm{Ar} / \mathrm{He}=4.5 / 5.5$ was supplied to the plasma stream at a constant rate of $100 \mathrm{~g} / \mathrm{min}$ and the current was maintained at $450 \mathrm{~A} / 90 \mathrm{~V}$. The distance between the spray gun and the base material to be coated was maintained at $150 \mathrm{~mm}$ and the powder was supplied at a flowrate of 3 liters per minute. In order to observe the voids formed on the surface, after cooling the fabricated thermal barrier coating layer specimens to room temperature, diamond suspensions of 10, 6, 3, and $1 \mu \mathrm{m}$ were used to polish the coating layer surface. Here, the thicknesses of the polished specimen were checked at each stage so that consistent polishing could be obtained; the final specimens all have the same coating layer thick- (a)

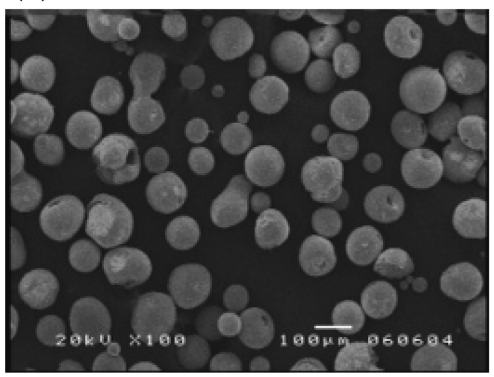

(b)

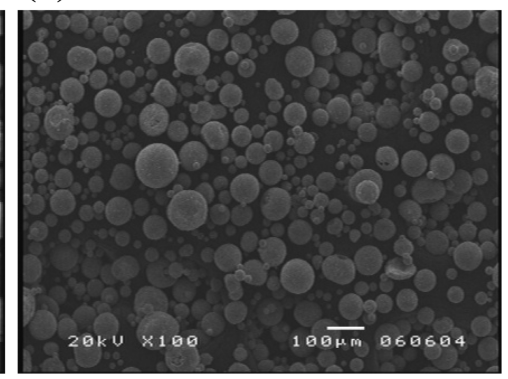

(c)

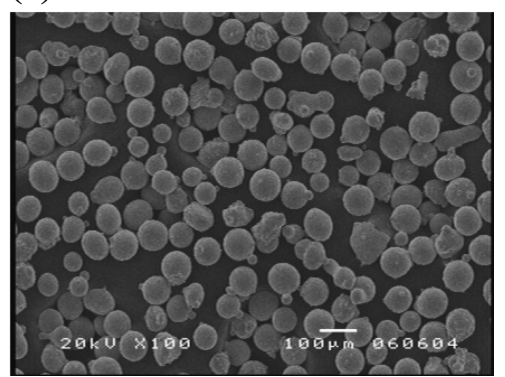

Fig. 2. SEM micrographs showing starting powders: (a) 204C-NS, (b) 204NS and (c) AMDRY 9625 
ness.

A high temperature thermal shock device was designed and manufactured: the specimen is installed within an alumina tube and the tube moves vertically in and out of a high temperature chamber, powered by an electric motor. Using this equipment, the temperature was increased at a rate of $5^{\circ} \mathrm{C}$ per minute and the specimen was exposed to the chamber at a temperature of $1100^{\circ} \mathrm{C}$ (hot zone) for a specific amount of time (5 min). Afterwards, a motor was used to lower the specimen and expose it to room temperature, where a rapid temperature change occurs, resulting in thermal shock. This cycle was repeated for 700, 900, 1050, and a maximum 1,200 cycles to carry out the thermal shock experimentation. After applying thermal shock through the high temperature/low temperature cycling, the formation of external fractures and delamination on the coating layer surface were observed.

In order to investigate whether mechanical property degradation occurred due to thermal shock, an indentation evaluation was used to measure the hardness and to implement the spherical indentation test. A micro-Vickers hardness tester (ASTM C1327-08, Mitutoyo, Japan) was used to measure the hardness. Indentation of $P=10 \mathrm{~N}$ was applied to the polished single layer and bilayer coating surface and the hardness $(H)$ was calculated using the equation below after measuring the diagonal length $2 a$ of the indentation mark.

$$
H=P / 2 a^{2}
$$

Mechanical property degradation after applying thermal shock to the specimen was assessed by using the Hertzian indentation method to measure the indenter displacement according to the indentation load. ${ }^{10,11)}$ The indenter used for the indentation was made of spherical tungsten carbide (WC) of $3.18 \mathrm{~mm}$ radius and the ball was installed in the jig of a material testing machine (Instron 5567, Instron Co., U. S. A). The indentation load was increased to $P=1000 \mathrm{~N}$ at a rate of $0.2 \mathrm{~mm} / \mathrm{min}$ and unloading was carried out at the same rate when the maximum load was reached. When increasing the load, an extensometer was used to measure the displacement for each level of loading. Ten points were measured in the coating layer. The average displacement value for each value of loading was calculated and used in the analysis. Also, porosity changes on the surface before and after thermal cycling and thermal shocks were observed using an optical microscope.

\section{Results and Discussion}

Figure 2 provides SEM images of the starting commercial granules used to coat the thermal barrier material. In order to fabricate a thermal barrier coating layer of uniform thickness and porosity, the powder has to be transported smoothly along with the gas flow during plasma spraying, so the granules have to be fabricated in spherical form and must have considerable strength. Additionally, it was reported that control of the shape, average particle size, and particle size distribution of the starting granules is important in order to control the microstructure, which affects the thermal barrier performance. ${ }^{12)}$ In this study, the thermal barrier coating layer was fabricated using commercial powders with similar particle sizes and differing particle shapes and size distribution, as shown in Table 1. Although observation of the 204C-NS powder, as shown in Fig. 2 (a), revealed hollow spherical type particles, the $204 \mathrm{NS}$ powder was of filled spherical type with relatively dense spherical material, as shown in Fig. 2 (b). Comparison of the 204C-NS and 204NS powder particle size distributions showed that while 204CNS was had a wide particle size distribution and was composed of variously sized particles, the $204 \mathrm{NS}$ powder composed of similarly sized particles and had a narrow particle size distribution. Meanwhile, Fig. 2 (c) provides an SEM image of the commercial bondcoat powder (AMDRY9625) used in this study; it was composed of spherical particles with a narrow particle size distribution.

Figure 3 shows XRD analyses of the 204C-NS and 204NS powders shown in Fig. 2. The analysis results of the XRD peaks are inserted with symbols. As shown in the analysis results graph, the powders were composed of tetra/cubic zirconia and monoclinic zirconia. Thus, regardless of the shape or type of the starting granules, they were all zirconia and had the same crystalline structure. In the case of monoclinic zirconia, the research team in this study previously reported that phase transformation to tetra/cubic structures occurred when the powder was exposed to high temperature after undergoing spray coating. Therefore, in this study, it was predicted that the monoclinic zirconia contained in the starting granules would undergo phase transformation to

Table 1. EDS Analysis of 204C-NS and 204-NS Powders

\begin{tabular}{|c|c|c|c|c|}
\hline & \multicolumn{2}{|c|}{ 204C-NS } & \multicolumn{2}{|c|}{$204 \mathrm{NS}$} \\
\hline Chemistry & \multicolumn{2}{|c|}{$\mathrm{ZrO}_{2} 8 \mathrm{wt} \% \mathrm{Y}_{2} \mathrm{O}_{3}$} & \multicolumn{2}{|c|}{$\mathrm{ZrO}_{2} 8 \mathrm{wt} \% \mathrm{Y}_{2} \mathrm{O}_{3}$} \\
\hline Particle size & $-125+45 \mu \mathrm{m}$ & & $-125+11 \mu \mathrm{m}$ & \\
\hline Element & Weight\% & Atomic\% & Weight\% & Atomic\% \\
\hline $\mathrm{O} \mathrm{K}$ & $28.23 \pm 3.61$ & $68.96 \pm 3.66$ & $28.08 \pm 4.66$ & $68.49 \pm 4.81$ \\
\hline Y L & $4.15 \pm 0.71$ & $1.85 \pm 0.40$ & $3.82 \pm 0.52$ & $1.71 \pm 0.33$ \\
\hline $\mathrm{Zr} \mathrm{L}$ & $67.61 \pm 3.22$ & $29.19 \pm 3.35$ & $68.13 \pm 4.31$ & $29.79 \pm 4.53$ \\
\hline Totals & \multicolumn{2}{|c|}{100.00} & \multicolumn{2}{|c|}{100.00} \\
\hline
\end{tabular}



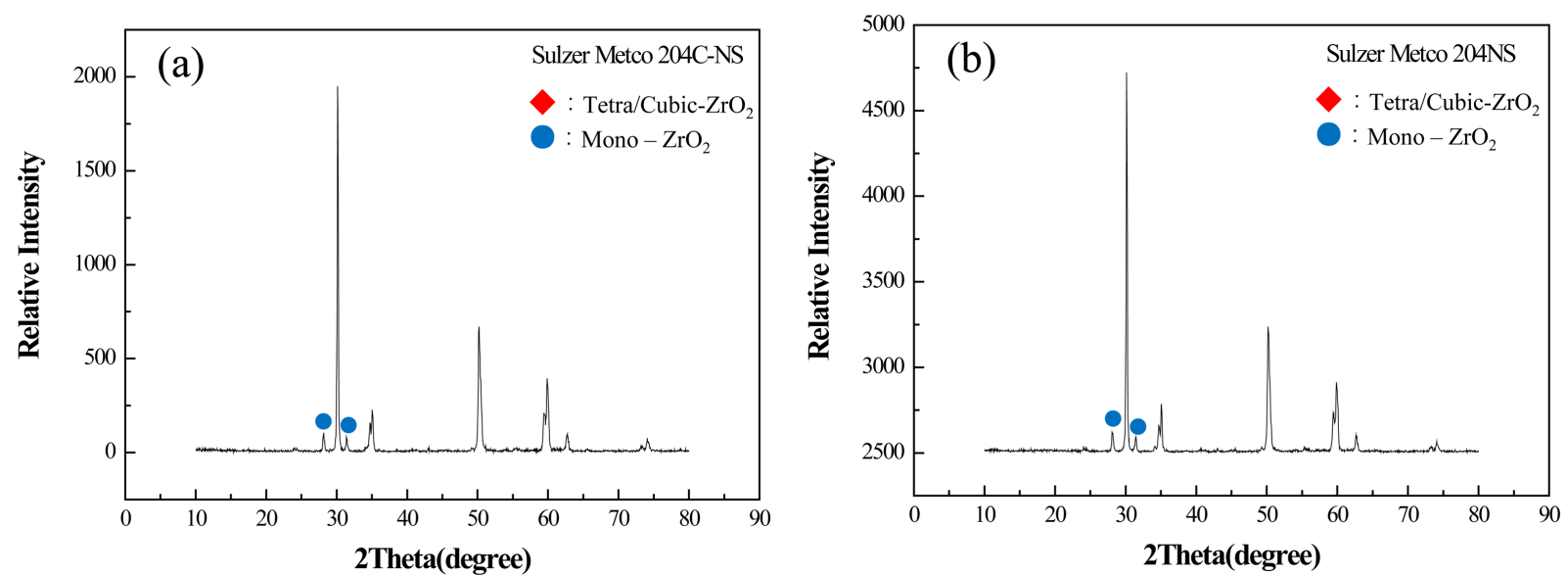

Fig. 3. XRD analysis result of TBCs granules (a) 204C-NS and (b) $204 \mathrm{NS}$.

tetra/cubic structures when plasma sprayed, and so it was thought that the issue of fracture formation due to volume expansion induced by the temperature change of the monoclinic material from high temperature back to room temperature would not arise. ${ }^{2)}$

The composition analysis results, obtainedby EDS of the starting granules, were organized into Table 1. Peaks corresponding to oxygen, zirconium, and yttrium were found and quantitative analysis revealed that the chemical compositions of the 204C-NS and 204NS powders were similar to each other. When considering the chemical composition of $\mathrm{Y}_{2} \mathrm{O}_{3}$ added to $\mathrm{ZrO}_{2}$, it was thought that around 8\% $\mathrm{Y}_{2} \mathrm{O}_{3}$ weight percent was added; this result had been reported in one work in the literature, in which the addition of $\mathrm{Y}_{2} \mathrm{O}_{3}$ to $\mathrm{ZrO}_{2}$ at optimal mass resulted in the highest durability. ${ }^{13}$

(a)

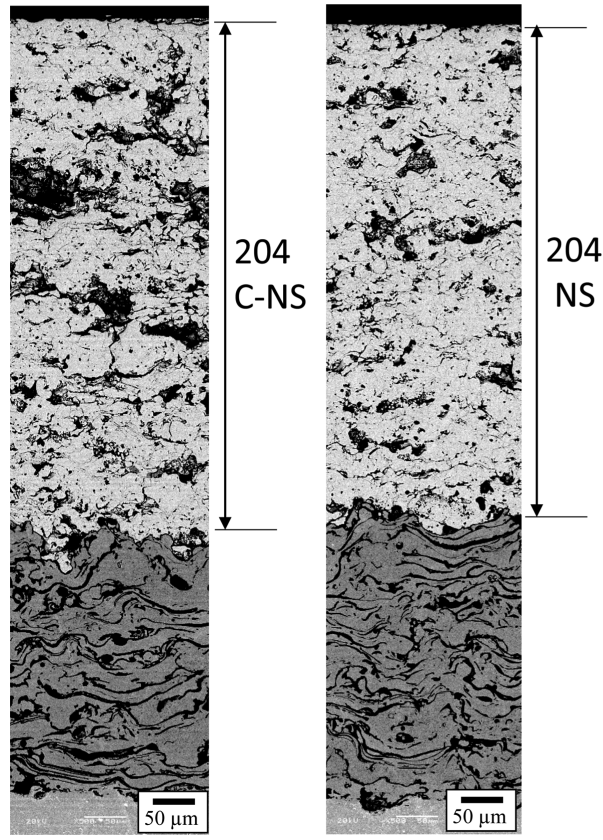

Figure 4 provides SEM observation images of the plasma sprayed coating layer cross section. Using air plasma spray (APS), the bondcoat powders were coated with to thickness of around $300 \mu \mathrm{m}$. Yttria stabilized zirconia was coated on top of that, so that the total thickness was $600 \mu \mathrm{m}$. Here, the different powders were coated in single layer or bilayer coatings. Fig. 4 shows the cross sections of the (a) $204 \mathrm{C}-\mathrm{NS}$ $600 \mu \mathrm{m}$ coating, (b) $204 \mathrm{NS} 600 \mu \mathrm{m}$ coating, (c) $204 \mathrm{NS} 300$ $\mu \mathrm{m}$ coating followed by $204 \mathrm{C}-\mathrm{NS} 300 \mu \mathrm{m}$ coating on top, and (d) reverse coating order of $204 \mathrm{C}-\mathrm{NS} 300 \mu \mathrm{m}$ coating followed by $204 \mathrm{NS} 300 \mu \mathrm{m}$ coating on top. Table 2 provides analyses of each cross-section image. As can be noted from the microstructure images, the 204C-NS powder coating layer had relatively larger pores and higher porosity than those of the $204 \mathrm{NS}$ powder coating layer. This was due to

(c)

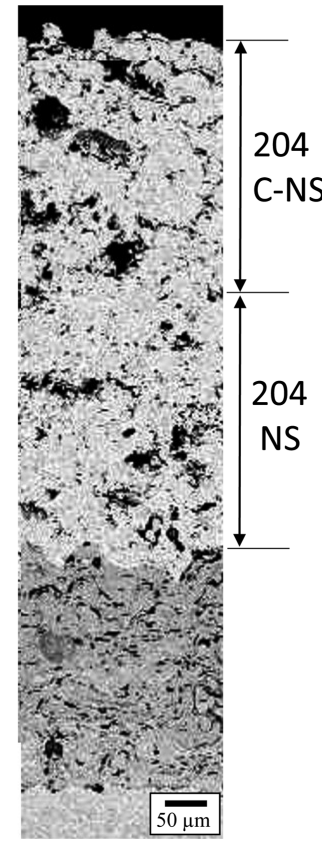

(d)

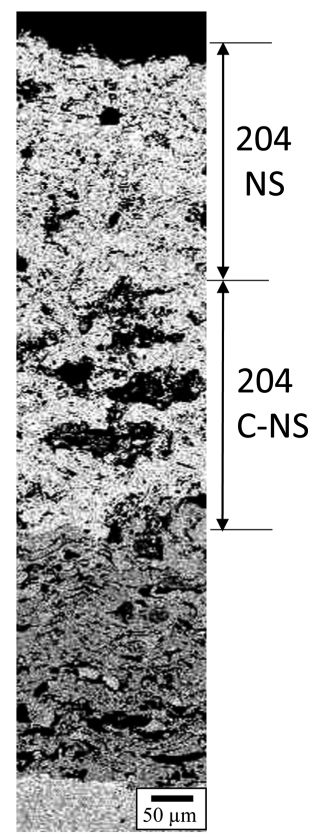

Fig. 4. SEM micrographs showing section of (a) 204C-NS, single layer, (b) 204NS, single layer, (c) 204C-NS/204NS bilayer and (d) $204 \mathrm{NS} / 204 \mathrm{C}-\mathrm{NS}$ bilayer. 
Table 2. Microstructural Analysis of TBCs with Single and Bilayer Structures in Topcoat

\begin{tabular}{ccccc}
\hline & \multicolumn{3}{c}{ Single } & \multicolumn{2}{c}{ Bilayer } \\
\hline Parameters & 204C-NS & 204 NS & 204C-NS/NS & 204 NS/C-NS \\
\hline Total porosity (\%) & 19.6 & 10.2 & 18.9 & 8.2 \\
Fraction of pores (\%) & 17.0 & 6.5 & 17.6 & 4.6 \\
Mean size of pores ( $\mu \mathrm{m})$ & 21.7 & 15.4 & 26.0 & 9.3 \\
\hline
\end{tabular}

the impact of the starting granules: the 204C-NS powder was composed of hollow spheres with a narrow particle size distribution, as found in Fig. 2. On the other hand, spray coating of the $204 \mathrm{NS}$ powder with dense filled spheres rather than hollow spheres, and with a relatively wide particle size distribution, resulted in the formation of a dense coating layer with relatively small pores and low porosity. Therefore, through this study, coating layers of different microstructures were fabricated using starting granules of different shapes and particle size distributions.

As explained above, mono and bilayer coating layers produced using different starting commercial powders were tested for 600, 900, 1050, and 1200 thermal shock cycles, in which the thermal shock was between the maximum temperature of $1100^{\circ} \mathrm{C}$ and room temperature. Then, the hardness of each specimen was measured; values are shown in the graph of Fig. 5, which provides the results for the (1) single coating layer and (b) bilayer coating. The figures show that regardless of the presence of single or bilayer coating, the hardness tended to increase as the thermal shock cycle number increased, periodically exposing the specimen to high temperature and inducing sintering phenomenon in the coating material. ${ }^{14,15)}$ Slope analysis of the load-displacement curve measured through the indentation testing of each coating layer revealed that for the single coating with $204 \mathrm{C}-\mathrm{NS}$ powder and the bilayer coating material with topmost layer of 204C-NS powder, coating led to large increases in the slope compared to the other coatings with $204 \mathrm{NS}$ powder. This change was thought to be due to the significant densification that occurred in the porous coating layer. It was indirectly shown that densification due to sintering was the cause of the hardness increase. ${ }^{15)}$ On the other hand, Fig. 5 (a) shows that the hardness of the coating layer fabricated with $204 \mathrm{NS}$ powder was relatively higher than that of the 204C-NS coating layer, while Fig. 5 (b) shows that the hardness of the bilayer coating layer with topmost layer of $204 \mathrm{NS}$ powder coating was relatively superior. This result was due to the microstructure, which had relatively large pores and lower porosity. Thus, it was determined that the densely coated case exhibited greater hardness regardless of whether the coating was single or bilayer. In addition, comparison of Fig. 5 (a) and (b) was conducted to analyze the effect of the bilayer coating layer. The hardness of the $204 \mathrm{C}-\mathrm{NS} / 204 \mathrm{NS}$ bilayer coating was about half of the hardness value of the single layer, but the hardness of the $204 \mathrm{NS} / 204 \mathrm{C}-\mathrm{NS}$ bilayer coating was almost identical to that of $204 \mathrm{NS}$. For $204 \mathrm{C}-\mathrm{NS} / 204 \mathrm{NS}$, it was thought that even the $300 \mu \mathrm{m}$ thick film coating was affected by the bottom layer. ${ }^{11)}$ The $204 \mathrm{NS} / 204 \mathrm{C}-\mathrm{NS}$ is also affected by the bottom layer, but it was found to be affected by the densification of the surface coating layer, which will be discussed later on. Therefore, the usage and coating order of different coating material powders were varied to fabricate bilayer thermal barrier coatings with different levels of hardness. Also, in the case of the bilayer material, the controls of hardness and porosity were possible using different layers. The 204NS/ 204C-NS bilayer coatingwas expected to be used as a coating layer with outstanding thermal barrier performance because of the high porosity in the bottom and the good hardness, similar to that of $204 \mathrm{NS}$.
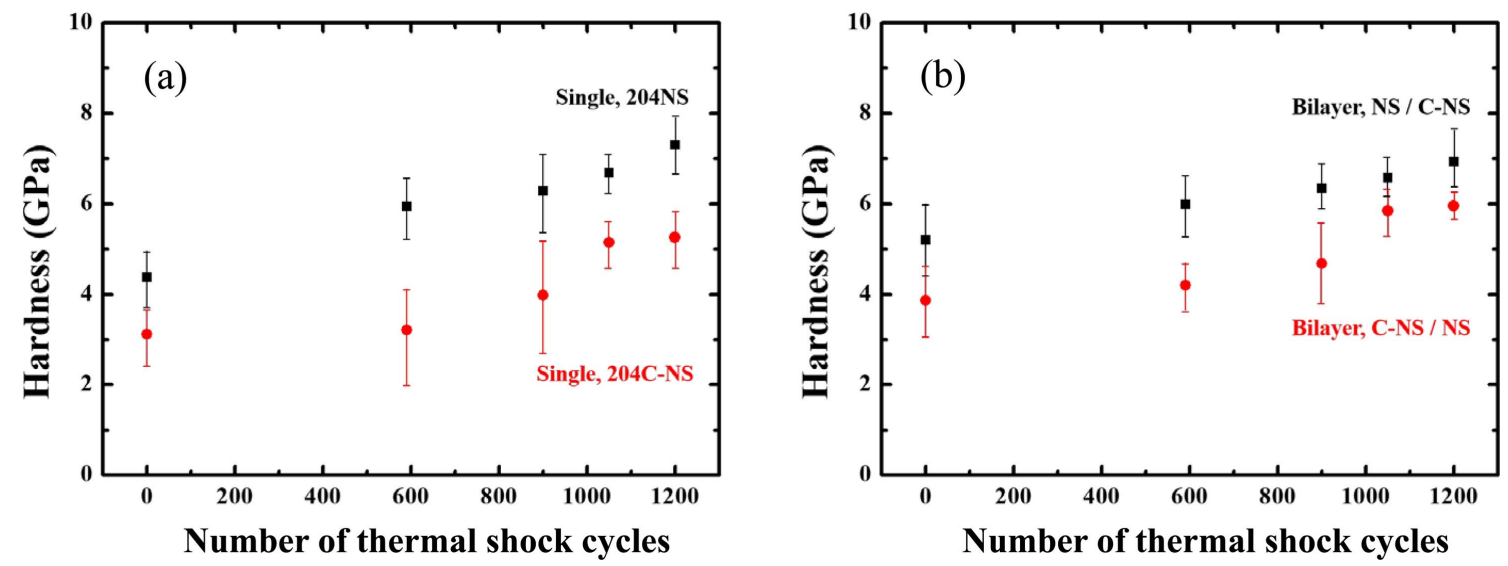

Fig. 5. Plots of hardness by Vickers indentation test after exposure to thermal shock test of (a) single layer TBCs and (b) bilayer TBCs. 
(a)

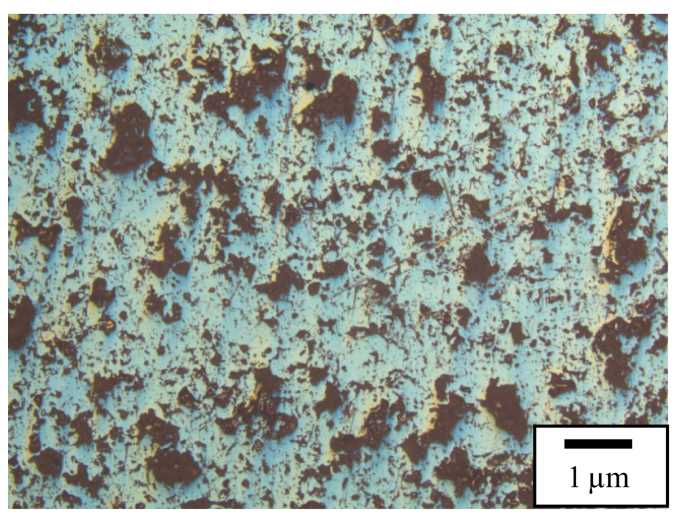

(c)

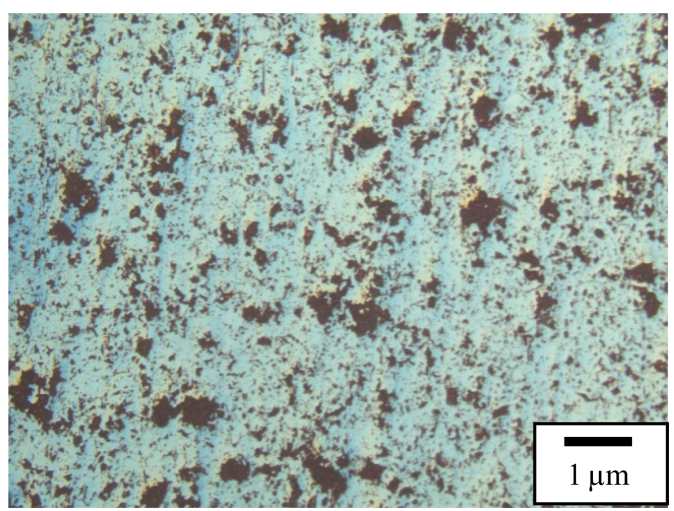

(b)

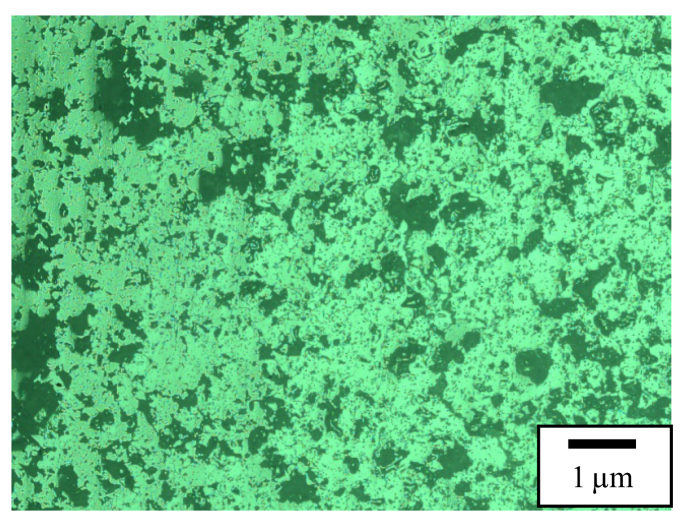

(d)

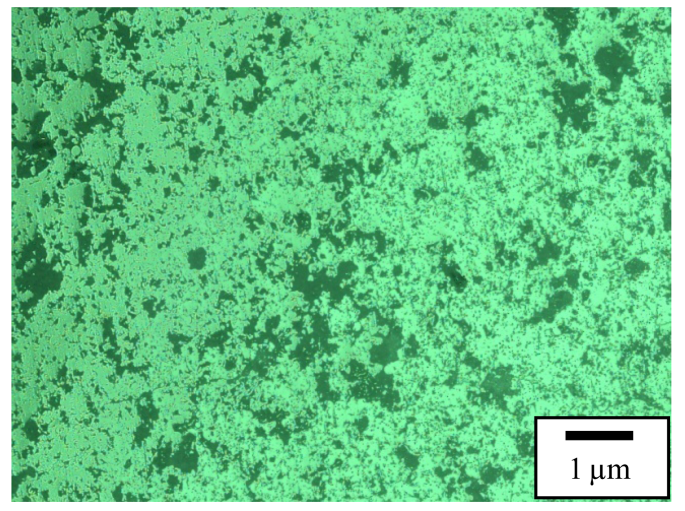

Fig. 6. Optical micrographs of surface of single layered TBC after exposure to thermal shock test of (a, c) 700 cycles and (b, d) 1,200 cycles on TBC (a, b) fabricated from 204C-NS and (c, d) 204-NS.

After conducting 700 and 1200 thermal shock cycles for the 204C-NS powder and 204NS powder single layer thermal barrier coatings under the same conditions, surfaces were observed through an optical microscope,with results shown in Fig. 6. Fig. 6 provides a (a) surface image of the 204C-NS coating layer after 700 thermal shock cycles and (b) surface image of the 204C-NS coating layer after 1200 cycles, while Fig. 6 (c) provides a surface image of the 204NS coating layer after 700 thermal shock cycles and (d) provides a surface image of the $204 \mathrm{NS}$ coating layer after 1200 cycles. As shown in the figures, the 204 NS coating was found to be relatively denser compared to the $204 \mathrm{C}-\mathrm{NS}$ coating layer and the surface microstructure of the coating layer after 1200 thermal shock cycles was denser than the surface microstructure after 700 thermal shock cycles. The average pore size decreased along with the porosity as the thermal shock cycle increased. Additionally, delamination and fracture did not occur even after 1200 thermal shock cycles; this shows the outstanding thermal durability of this material at $1100^{\circ} \mathrm{C}$.

After conducting 700 and 1200 thermal shock cycles for the 204C-NS/204NS bilayer coating and 204NS/204C-NS bilayer coating under the same conditions, the surfaces were observed through an optical microscope; results are shown in Fig. 7. Fig. 7 provides a surface image of the 204CNS powder coated on top of the plasma sprayed 204NS powder after (a) 700 thermal shock cycles and (b) 1200 cycles, whereas (c) and (d) provide surface images of the 204NS powder coated on top of the plasma sprayed 204C-NS powder after 700 and 1200 thermal shock cycles, respectively. As can be seen in the figures, the 204NS coating was found to be denser compared than that with 204C-NS coated on the top layer; the surface microstructure of the coating after 1200 thermal shock cycles had a denser structure compared to the surface microstructure after 700 thermal shock cycles. Compared to Fig. 6, it was found that the thermal shock testing of the 204NS bilayer material resulted in the densest sintering, which is thought to cause the hardness improvement found in Fig. 5 (b). Meanwhile, delamination and fractures did not occur for the thermal barrier coating fabricated in bilayer after 1200 thermal shock cycles, revealing the outstanding thermal durability of that material.

Figure 8 (a) provides a load-displacement curve obtained when an indenter of $\mathrm{r}=3.18 \mathrm{~mm}$ radius was used to indent the polished TBC surface up to a load of $P=1000 \mathrm{~N}$ at a rate of $0.2 \mathrm{~mm} / \mathrm{min}$; load was then removed at the same rate. As can be seen in the representative indentation load-displace- 
(a)

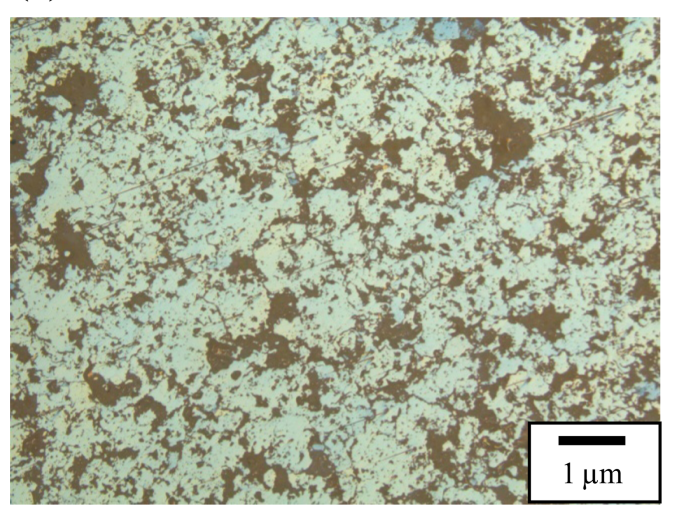

(c)

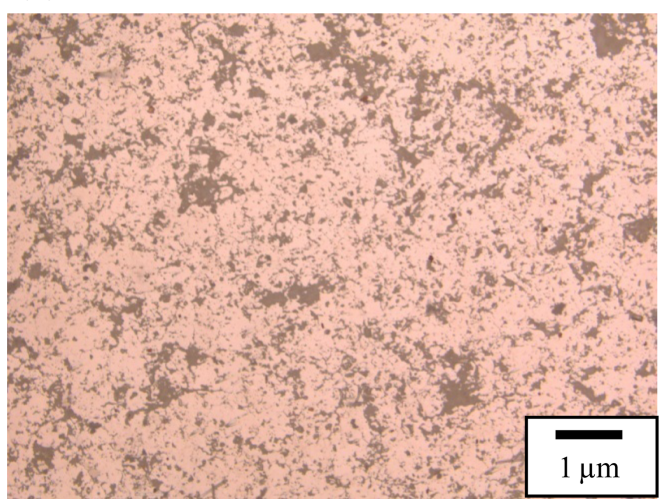

(b)

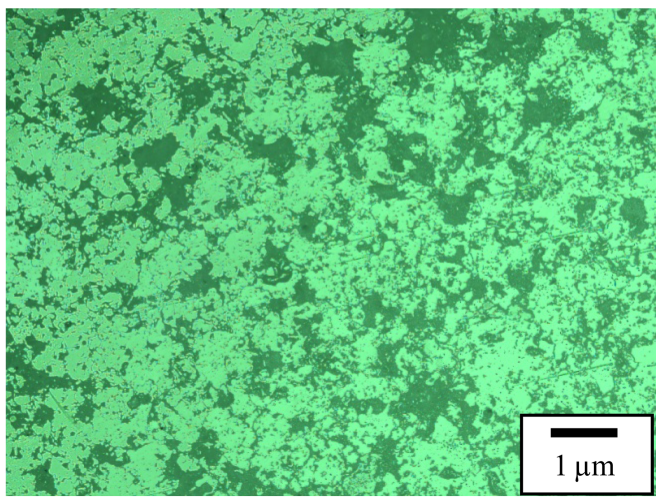

(d)

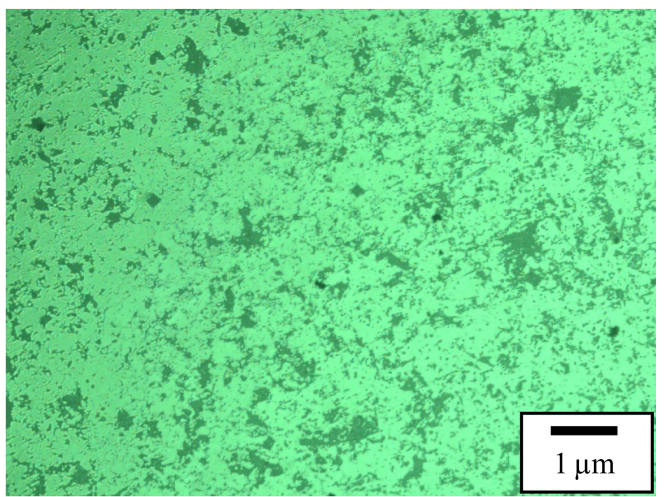

Fig. 7. Optical micrographs of surface of bilayer TBC after exposure to thermal shock test of (a, c) 700 cycles and (b, d) 1,200 cycles on TBC (a, b) fabricated from 204C-NS/204NS and (c, d) 204-NS/204C-NS.

ment curve, the coating with a single layer of zirconia on top of the bondcoat underwent 700, 900, 1050, and 1200 thermal shock cycles; this was followed by indentation testing, used to obtain the indentation-load displacement curve shown in Fig. 8 (a). As the slope of the indentation-load displacement curve under loading and the slope of the tangent to the curve, obtained by removing the loading, are related to the Young's modulus of the material, ${ }^{15)}$ the slopes of the indentation-load displacement curves for all the indentation specimens were determined and are shown in Fig. 8 (b). As can be seen in the graph, the slope increased as the thermal shock cycle increased from 700 to 1200 cycles. In the case of the relatively porous $204 \mathrm{C}-\mathrm{NS}$ coating material, the elasticity slope value sharply increased due to the rapid sintering
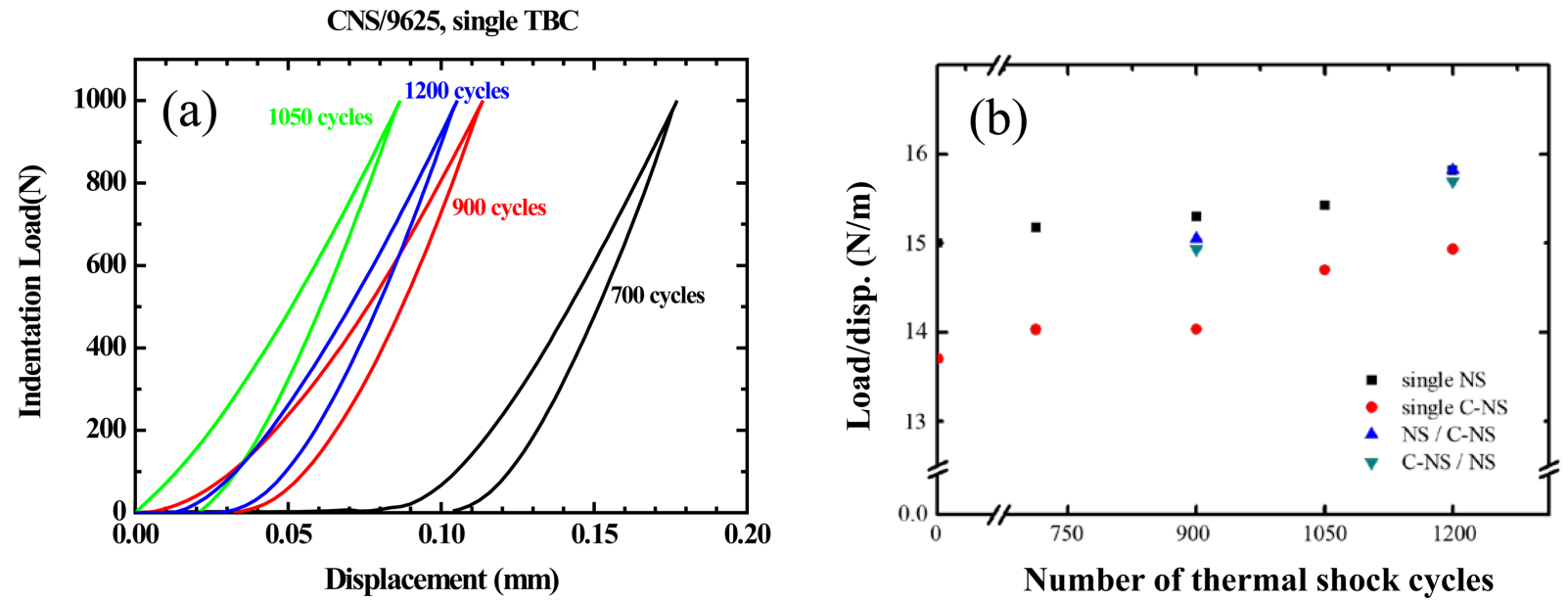

Fig. 8. Plots of indentation load-displacement by Hertzian indentation test after exposure to thermal shock test of (a) single layer TBCs and (b) indentation load-displacement gradient. 
phenomenon. It was thought that the Young's modulus increased due to the sintering phenomenon as the thermal shock cycle number increased. Thus, this change was the macroscopic result of the densification via microscopic porosity reduction. Moreover, the hardness corresponding to the residual strain of the indentation load-displacement curve also showed a tendency to increase according to the thermal shock cycling; this result was in agreement with the trend shown in Fig. 5.

With regard to the bilayer coating case, although the loaddisplacement slope (elasticity) value was within the single layer slope value, as shown in Fig. 8 (b), the value was similar to that of the single layer 204-NS coating material, which was relatively outstanding. Also, in contrast to the single layer case, the elasticity slope value did not change significantly during thermal shock cycling up to 1200 cycles. This result shows that the multilayer coating material exhibited excellent thermal durability.

\section{Conclusions}

In order to assess whether mechanical property degradation of high temperature gas turbine components occurs due to thermal shock, the air plasma spray method was employed using different commercial powders (204C-NS and 204NS) for a single layer and bilayer coating. A bondcoat $300 \mu \mathrm{m}$ thick was applied to a heat-resistant alloy and partially stabilized zirconia was coated on top of the bondcoat to result in a total layer thickness of $600 \mu \mathrm{m}$. Here, the bilayer coating used different powders (204C-NS and $204 \mathrm{NS}$ ), in which each was used for $300 \mu \mathrm{m}$ of coating to fabricate thermal barrier coating layers by varying the powder coating order.

To assess hardness changes, thermal shock testing of 700 , 900,1050 , and 1200 cycles from $1100^{\circ} \mathrm{C}$ to room temperature was carried out on the single layer or bilayer zirconia thermal barrier coating layer formed specimens. Also, to investigate changes in the mechanical properties, the slopes of the indentation load-displacement curves were determined. Additionally, the microstructures were investigated using an optical microscope and scanning electron microscope, and the following conclusions were obtained.

1) By using different commercial YSZ powders (204C-NS and $204 \mathrm{NS}$ ), a relatively porous thermal barrier coating and dense thermal barrier coating were fabricated due to the different shapes and particle size distributions of the powders.

2) The thermal cycling test results showed that delamination did not occur after 1200 cycles at temperatures under $1100^{\circ} \mathrm{C}$; however, densification occurred due to periodic exposure to high temperature, in which the degree of densification varied depending on the powder type and presence of bilayer coating.

3) The hardness test results revealed that the hardness showed a tendency to increase due to densification phenomenon during thermal cycling, regardless of whether there was a single layer or bilayer coating; the bilayer coating allowed for controlling of the hardness. In particular, the hardness of the $204 \mathrm{NS} / 204 \mathrm{C}-\mathrm{NS}$ bilayer coating was found to be similar to that of the single layer coating.

4) After thermal shock testing, for comparative analysis, load-displacement curves were obtained through indentation testing; these curves showed that the elasticity and hardness tended to increase as the thermal shock cycle number increased, and the thermal durability of the bilayer material was determined to be outstanding, as were the mechanical properties.

\section{Acknowledgements}

This work was supported by the IT R\&D program of MOTIE/KEIT [NO. 10043795, Development of Materials for Gas Turbine Operated at $1600^{\circ} \mathrm{C}$ for High-Efficiency Power Generation]; we wish to thank Prof. Yeon-Gil Jung for the experimental analysis and discussions.

\section{REFERENCES}

1. A. Rabiei and A. G. Evans, "Failure Mechanisms Associated with the Thermally Grown Oxide in Plasma-Sprayed Thermal Barrier Coatings," Acta Mater., 48 [15] 3963-76 (2000).

2. J. H. Cho, T. W. Kim, Y. G. Jung, and K. S. Lee, "Thermal and Mechanical Evaluation of the Thermal Barrier Layers Coated by Spray Dried Granules," J. Ceram. Process. Res., 10 [3] 344-50 (2009).

3. K. S. Lee, D. H. Lee, and T. W. Kim, "Microstructure Controls in Gadolinium Zirconate/YSZ Double Layers and Their Properties," J. Ceram. Soc. Jpn., 122 [1428] 668-73 (2014).

4. A. G. Evans, D. R. Mumm, J. W. Hutchinson, G. H. Meier, and F. S. Pettit, "Mechanisms Controlling the Durability of Thermal Barrier Coatings," Prog. Mater. Sci., 46 [5] 505-53 (2001).

5. M. Watanabe, C. Mercer, C. G. Levi, and A. G. Evans, "A Probe for the High Temperature Deformation of Thermal Barrier Oxides," Acta Mater., 52 [6] 1479-87 (2004).

6. A. G. Evans and J. W. Hutchinson, "The Mechanics of Coating Delamination in Thermal Gradients," Surf. Coat. Technol., 201 [18] 7905-16 (2007).

7. D. H. Lee, T. W. Kim, and K. S. Lee, "Design of Thermal Barrier Coatings using Gadolinium Zirconate Ceramics: A Study on Gadolinium Zirconate/YSZ Bilayers," J. Ceram. Soc. Jpn., 117 [1365] 550-54 (2009).

8. S. W. Myoung, J. H. Kim, W. R. Lee, Y. G. Jung, and K. S. Lee, "Microstructure Design and Mechanical Properties of Thermal Barrier Coatings with Layered Top and Bond Coats," Surf. Coat. Technol., 205 [5] 1229-35 (2010).

9. K. S. Lee, S. K. Lee, B. R. Lawn, and D. K. Kim, "Contact Damage and Strength Degradation in Brittle/Quasi-Plastic Silicon Nitride Bilayers," J. Am. Ceram. Soc., 81 [9] 2394-404 (1998).

10. B. R. Lawn, "Indentation of Ceramics with Spheres: A Century after Hertz," J. Am. Ceram. Soc., 81 [8] 1977-94 
(1998).

11. D. H. Lee and K. S. Lee, "Mechanical Behavior of Layered YSZ Thermal Barrier Coatings using Indentation Test," J. Korean Ceram. Soc., 48 [5] 396-403 (2011).

12. G. Bertrand, P. Bertrand, P. Roy, C. Rio, and R. Mevrel, "Low Conductivity Plasma Sparyed Thermal Barrier Coatings using Hollow PSZ Spheres: Correlation between Thermophysical Properties and Microstructure," Surf. Coat. Technol., 202 [10] 1994-2001 (2008).

13. F. Press, "Optimization of the NiCrAI-Y/ZrO $\mathrm{Z}_{2}-\mathrm{Y}_{2} \mathrm{O}_{3}$ Ther- mal Barrier System," (NASA, Lewis Research Center, Cleveland, OH, 1985).

14. D. H. Lee, N. K. Kang, K. S. Lee, H. S. Moon, H. T. Kim, and C. Kim, "Evaluation of Thermal Durability of Thermal Barrier Coating and Change in Mechanical Behavior," J. Korean Ceram. Soc.,54 [4] 314-22(2017).

15. W. C. Oliver and G. M. Pharr, "An Improved Technique for Determining Hardness and Elastic Modulus using Load and Displacement Sensing Indentation Experiments," J. Mater. Res., 7 [6] 1564-83 (1992). 